\title{
ROLE OF LAPAROSCOPY TO OBVIATE LAPAROTOMY IN VIOLATING ABDOMINAL STAB WOUNDS IN HEMODYNAMICALLY STABLE PATIENT
}

\author{
Emad El-din Farid, Shaban Mohamed Mohamed Abd-El-Mageed, \\ Dina Hany Ahmed and Mohamed Kamel Safina*
}

\begin{abstract}
Department of General Surgery - Faculty of Medicine, Ain Shams University, Cairo, Egypt

\section{Corresponding Author:}

Mohamed Kamel Safina

Mobile: 01098334245.

\section{E-mail:}

mkamelsafena@yahoo.com

Received: 9/7/2020

Accepted: 29/7/2020

Online ISSN: 2735-3540
\end{abstract}

\begin{abstract}
:
Background: Abdominal trauma one of the main series proplem faced in emergency room it is management is directly related to the incidence of morbidity and mortality Laparoscopy approach has gained wide acceptance among all surgeon.
\end{abstract}

Aim of the work: To study role of laparoscopy in management of violating abdominal stab wounds in hemodynamically stable patients regarding current applications, advantages, disadvantages and future developments.

Patients and methods: This prospective nonrandomized clinical study included 80 patients who presented to Ain Shams emergency unit with anterior abdominal stab wound(s) during the period from January 2018 till January 2019. Informed consent regarding conservative management or the need for diagnostic laparoscopy / laparotomy was obtained from all patients.

Results: In our study results of 80 patients showed 15 patients (18.8\%) were negative without intraabdominal lesion.

65 patients (81.3\%) had positive finding 46 patients $(57.5 \%)$ were managed by laparoscopy and 19 patients (23.8\%) were converted to open surgery.

46 patients were managed by laparoscopy 12 (15\%) patients underwent repair of serosal and small tears with simple intracoporcal suturing.

10 patients $(12.5 \%)$ with omental injury, cauterization was done to the 8 patients and clipping of omental bleeder in 2 patients was done.

8 patients (10\%) with gastric tear were repaired by intracoporial suturing.

11 patients $(13.8 \%)$ with liver injury, haemostasis was done by cauterization and gel foam.

5 patients with left colonic and sigmoid injuries underwent lap. colostomy.

Conclusion: Exploratory laparoscopy applied to carefully selected hemodynamically stable penetrating trauma patients proved to be safe and technically feasible. It also reduced the negative and non-therapeutic laparotomies and offered profound therapeutic potential and cost effectiveness. So 61 patients (76.3\%) ovoid unnecessary laparotomy [15 negative $(8.8 \%)+46(57.5 \%)$ underwent laparoscopic management] so it's proved to both diagnostic and therapeutic role 
Keywords: Laparoscopy shoule be the first choise of this type of selected trauma and patient.

\section{INTRODUCTION:}

Abdominal trauma is a significant source of morbidity and mortality with the penetrating and blunt mechanisms of injury, its rapid diagnosis is essential in order to minimize morbidity ${ }^{(\mathbf{1})}$.

The focus of modern trauma management is on appropriate and timely surgical intervention. Abdominal penetrating wounds have been treated historically by different methods. Prior to World War I, PAI was managed expectantely. During World War II, studies showed that early laparotomy improved survival. By the late 1950 s, routine laparotomy was the standard treatment for PAI. Over the last 30years the pendulum shifted towards selective mananagement, initially involving only SW and later including GSW. The introduction and refinement of diagnostic procedures and imaging studies, such as laparoscopy, computed tomographic CT scan, and focused abdominal sonography for trauma (FAST), has contributed significantly in the new trends of PAI management ${ }^{(2)}$.

Laparoscopy remains debatable regarding its optimum role in the setting of penetrating abdominal trauma, although it can offer advantages over traditional local wound exploration. Nevertheless, laparoscopy can be a screening, diagnostic and therapeutic tool in penetrating abdominal trauma thus, reducing the incidence of unnecessary laparotomy ${ }^{(3)}$.

Diagnostic laparoscopy has been in use since the last century. Advances in technology, coupled with increasing evidence of enhanced outcomes following its use, have renewed interest in this modality. Diagnostic laparoscopy guides surgeons in preventing unnecessary laparotomies $^{(4)}$. There are a number of advantages to the patient with laparoscopic surgery versus an open procedure. These include reduced pain due to smaller incisions, faster healing, shorter recovery time and faster return to work ${ }^{(\mathbf{5})}$. However with advancement in techniques and equipments, it 'MAY' happen so that laparoscopy may replace laparotomy in near coming future ${ }^{(6)}$.

\section{AIM OF THE WORK:}

To study role of laparoscopy in management of violating abdominal stab wounds in hemodynamically stable patients regarding current applications, advantages, disadvantages and future developments.

\section{PATIENTS AND METHODS}

This prospective nonrandomized clinical study included 80 patients who presented to Ain Shams emergency unit with anterior abdominal stab wound(s) during the period from January 2018 till January 2019. Informed consent regarding conservative management or the need for diagnostic laparoscopy / laparotomy was obtained from all patients.

Inclusion criteria: All hemodynamically stable patients with violating abdominal stab wound(s).

Exclusion criteria: Hemodynamic instability (systolic blood pressure $<90 \mathrm{~mm}$ $\mathrm{Hg}$, heart rate $>100$ beats per minute. Posterior and flank abdominal stab wounds. Signs of peritonitis. Clinical evidence of bowel or omental evisceration. And other associated injuries other than abdomen.

All patients were done by the same surgical team which is experienced in laparoscopy. 


\section{Methods of the study:}

For those patients the following was done:

(I) Primary survey: Patent air way was ensured with cervical spine control. Stable breathing with no hemothorax or pneumothorax. And circulation application of 2 wide bore cannula and IV fluids urinary catheter and ryle were applied.

(II) Second survey assessment from head to toe to exclude injuries in all systems:

(1) History: It includes: The time of injury, type of weapon (e.g., knife, handgun, rifle, or shotgun), distance from the assailant (particularly important with shotgun wounds, as the likelihood of major visceral injuries decreases beyond the 10 foot or (3meter range), number of stab wounds or shots sustained., and the amount of external bleeding from the patient noted at the scene. If possible, important additional information to obtain from the patient includes the magnitude and location of any abdominal pain.

(2) Physical Examination: Included: inspection, auscultation, percussion, and palpation. This was followed by assessment of pelvic stability; urethral, perineal, and rectal exam; vaginal exam; and gluteal exam. The findings, whether positive or negative, should be documented carefully in the patient's medical record.

(3) FAST to detect any collection or splenic or hepatic laceration.

(4) X-Rays for abdominal trauma to detect air under diaphragm:

Preoperative preparation: Including shaving of the whole abdomen and lower chest just before operation and umbilicus cleaned well. Patients receive one dose of antibiotic one hour before operation. Insure blood \& plasma already prepared. All patients subjected to diagnostic laparoscopy were informed that conversion to laparotomy may be required and management will be according to the finding.

Operative technique: Position: supine. UL: abducted. LL: elastic stocks. Anesthesia: general. Sterilization: from nipple to mid-thigh. Monitor: above pt head. Surgeon: Lt side. Cameraman: Lt side. Assistant: Rt side. Nurse: Rt side.

The procedure was always performed under general anesthesia. Inflation of the abdomen with pressure 12-14 $\mathrm{mmHg}$. Pneumoperitoneum should be slowly and Special attention was given to the possibility of a tension pneumothorax caused by the pneumoperitoneum due to an unsuspected diaphragmatic rupture. The pneumoperitoneum was created in all patients through a periumbilical incision using open technique. Diagnostic laparoscopy was achieved through a10mm umbilical port. A30 degree laparoscopic camera (10mm in diameter) allowed optimal visualization of abdominal wall, diaphragm, liver and spleen dome. Tilting the bed in Trendelenburg position or reverse Trendelenburg position allowed visualization of lower and upper abdomen. For paracolic gutters exploration lateral tilting was required in most cases, visceral handling was necessary and easily carried out with $5 \mathrm{~mm}$ non-traumatic bowel graspers through two paramedian $5 \mathrm{~mm}$ ports placed on both sides at the level of the umbilicus.

Performing a full laparoscopic exploration of the abdominal cavity in search for injuries requires a systematic approach which follows all principles of open exploratory laparotomy. Indirect signs of bowel injury such as digestive fluids or purulent liquids were carefully looked for. A laparoscopic full Kocher maneuver is accomplished in right lateral decubitus, the hepatic flexure of the colon was mobilized to the left side using the harmonic scalpel. The peritoneum is incised lateral to duodenum and blunt dissection mobilizes the duodenum 
medially in order to explore its dorsal aspect. The lesser sac was opened through the gastrocolic ligament, allowing visualization of the posterior wall of the stomach as well as the body and tail of pancreas. Any small bowel perforations detected were simply sutured (3-0 vicryl). If segmental resection was needed, a mini-laparotomy was performed by extending the umbilical port to permit laparoscopy-assisted extracorporeal surgery. Bleeding from torn mesentery was controlled by clipping during laparoscopy.

Statistical analysis: Data were analyzed using Statistical Program for Social Science (SPSS) version 24. Quantitative data were expressed as mean \pm standard deviation
(SD). Qualitative data were expressed as frequency and percentage. Chi-square test: was used when comparing between nonparametric data. P-value $<0.05$ was considered significant. $\mathrm{P}$-value $<0.001$ was considered as highly significant. P-value > 0.05 was considered insignificant.

\section{RESULTS:}

This prospective nonrandomized clinical study included 80 patients who presented to Ain Shams emergency unit with anterior abdominal stab wound(s) during the period from January 2018 till January 2019.

Table (1): Description of demographic data and risk factors of all studied patients.

\begin{tabular}{|c|c|c|c|c|}
\hline \multicolumn{3}{|c|}{ Demographic data \& Risk factors } & \multirow{2}{*}{\multicolumn{2}{|c|}{$\frac{\text { Studied patients }(\mathrm{N}=80)}{36.1 \pm 11.5}$}} \\
\hline \multirow{4}{*}{ 宊 } & \multirow{4}{*}{$\begin{array}{c}\text { Age (years) } \\
\text { Sex }\end{array}$} & Mean \pm SD & & \\
\hline & & Min - Max & \multicolumn{2}{|c|}{$15-57$} \\
\hline & & Male & 74 & $92.5 \%$ \\
\hline & & Female & 6 & $7.5 \%$ \\
\hline \multirow{4}{*}{ 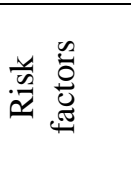 } & \multirow[t]{2}{*}{ DM } & No & 65 & $81.3 \%$ \\
\hline & & Yes & 15 & $18.8 \%$ \\
\hline & \multirow[t]{2}{*}{ HTN } & No & 69 & $86.3 \%$ \\
\hline & & Yes & 11 & $13.8 \%$ \\
\hline
\end{tabular}

This table shows the description of demographic data and risk factors of all studied patients. As regard age, the mean age of all studied patients was $36.1 \pm 11.5$ years with minimum age of 15 years and maximum age of 57 years. As regard sex, there were 74 males $(92.5 \%)$ and 6 females (7.5\%) in the studied patients. As regard risk factors, there were 11 hypertensive patients $(13.8 \%)$ and 15 diabetic patients $(18.8 \%)$ in the studied patients.

Table (2): Description of wound type in all studied patients.

\begin{tabular}{|l|c|c|c|}
\hline \multicolumn{2}{|c|}{} & \multicolumn{2}{|c|}{ Studied patients (N = 80) } \\
\hline \multirow{3}{*}{ Wound type } & Stab wound & 15 & $18.8 \%$ \\
\cline { 2 - 4 } & Gun-shot wound & 38 & $47.5 \%$ \\
\cline { 2 - 4 } & Sharp object wound & 27 & $33.8 \%$ \\
\hline
\end{tabular}

This table shows the description of wound type in all studied patients. There were 15 patients $(18.8 \%)$ with stab wound,
38 patients $(47.5 \%)$ with gun-shot wound and 27 patients $(33.8 \%)$ with sharp object wound in the studied patients. 
Table (3): Description of laparoscopic findings and management in all studied patients.

\begin{tabular}{|c|c|c|c|}
\hline \multirow{2}{*}{} & \multicolumn{2}{|c|}{ Studied patients $(\mathrm{N}=80)$} \\
\hline \multirow{3}{*}{$\begin{array}{c}\text { Laparoscopic } \\
\text { findings }\end{array}$} & Negative & 15 & $18.8 \%$ \\
\cline { 2 - 4 } & Intestinal injury & 26 & $32.5 \%$ \\
\cline { 2 - 4 } & Omental injury & 10 & $12.5 \%$ \\
\cline { 2 - 4 } & Gastric tear & 8 & $10 \%$ \\
\cline { 2 - 4 } & Liver injury & 11 & $13.8 \%$ \\
\cline { 2 - 4 } & Colonic injury & 10 & $12.5 \%$ \\
\hline
\end{tabular}

This table shows the description of laparoscopic findings and management in all studied patients. As regard laparoscopic findings, there were 15 patients (18.8\%) negative, 26 patients $(32.5 \%)$ with intestinal injury, 10 patients $(12.5 \%)$ with omental injury, 8 patients $(10 \%)$ with gastric tear, 11 patients $(13.8 \%)$ with liver injury and 10 patients $(12.5 \%)$ with colonic injury.

Table (4): Classification of studied patients as regard procedure of management.

\begin{tabular}{|c|c|c|c|c|}
\hline \multicolumn{2}{|c|}{} & \multicolumn{2}{|c|}{ Groups } \\
\cline { 3 - 4 } & Negative & Lap. Management & Converted to open \\
\hline $\begin{array}{c}\text { Studied patients }(\mathbf{n}= \\
\mathbf{8 0})\end{array}$ & $\mathbf{N}$ & 15 & 46 & 19 \\
\cline { 2 - 5 } & $\%$ & $18.8 \%$ & $57.5 \%$ & $23.8 \%$ \\
\hline
\end{tabular}

The study was conducted on 80 patients. There were classified into 3 groups, 15 patients $(18.8 \%)$ were negative, 46 patients $(57.5 \%)$ were managed by laparoscope and 19 patients $(23.8 \%)$ were converted to open surgery.

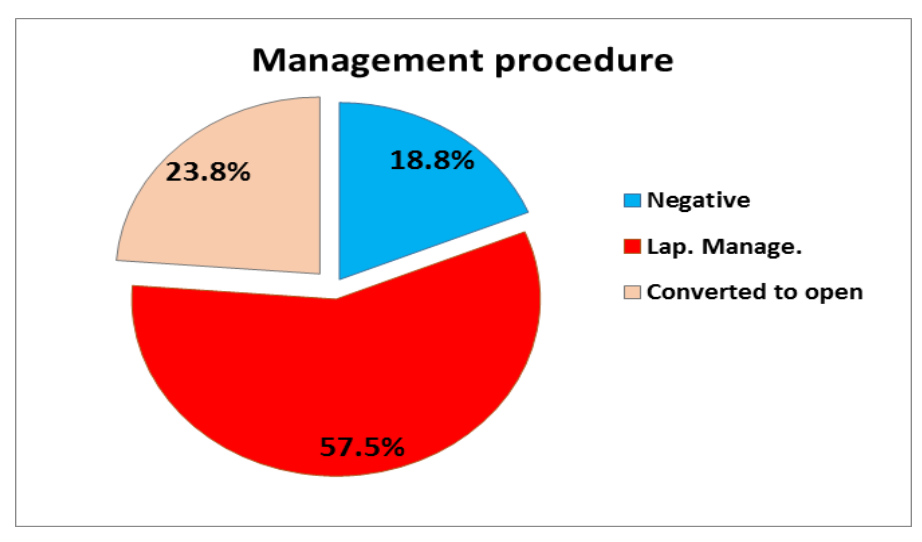

Figure (1): Classification of studied patients as regard procedure of management.

46 patients $(57.5 \%)$ managed by laparoscopy included 12 patients $(15 \%)$ with intestinal injury underwent direct repair, 10 patients $(12.5 \%)$ with omental injury, cauterization was done to the 8 patients and clipping of omental bleeder in 2 patients was done, 8 patients $(10 \%)$ with gastric tear were repaired by intracoporial suturing, 11 patients (13.8\%) with liver injury, haemostasis was done by cauterization and gel foam, 5 (6.3\%) patients with left colonic an dsigmoid injuries underwent lap. colostomy. 
Table (5): Comparison between studied groups as regard post-operative hospital stay.

\begin{tabular}{|c|c|c|c|c|c|c|c|c|c|}
\hline & & \multicolumn{2}{|c|}{$\begin{array}{l}\text { Negative } \\
(n=15)\end{array}$} & \multicolumn{2}{|c|}{$\begin{array}{l}\text { Lap. Mange. } \\
\qquad(\mathrm{n}=46)\end{array}$} & \multicolumn{2}{|c|}{$\begin{array}{l}\text { Con. To open } \\
\quad(\mathrm{n}=19)\end{array}$} & $\mathrm{X}^{2}$ & p-value \\
\hline \multirow{5}{*}{$\begin{array}{l}\text { Post-operative hospital } \\
\text { stay }\end{array}$} & 1 day & 15 & $100 \%$ & 2 & $4.3 \%$ & 0 & $0 \%$ & \multirow[t]{5}{*}{98.3} & \multirow{5}{*}{$\begin{array}{l}<0.001 \\
\quad \text { HS }\end{array}$} \\
\hline & 2 days & 0 & $0 \%$ & 28 & $60.9 \%$ & 2 & $10.5 \%$ & & \\
\hline & 3 days & 0 & $0 \%$ & 10 & $21.7 \%$ & 3 & $15.8 \%$ & & \\
\hline & 4 days & 0 & $0 \%$ & 0 & $0 \%$ & 1 & $5.3 \%$ & & \\
\hline & 5 days & 0 & $0 \%$ & 6 & $13 \%$ & 13 & $68.4 \%$ & & \\
\hline
\end{tabular}

$\mathrm{X}^{2}$ : Chi-square test.

HS: p-value $<0.001$ is considered highly significant.

This table shows highly statistical significant difference $(\mathrm{p}$-value $<0.001$ )

between studied groups as regard postoperative hospital stay.

Table (6): Comparison between studied groups as regard post-operative complications.

\begin{tabular}{|c|c|c|c|c|c|c|c|c|c|}
\hline & & \multicolumn{2}{|c|}{$\begin{array}{l}\text { Negative } \\
(n=15)\end{array}$} & \multicolumn{2}{|c|}{$\begin{array}{l}\text { Lap. Mange. } \\
\qquad(\mathrm{n}=46)\end{array}$} & \multicolumn{2}{|c|}{$\begin{array}{l}\text { Con. To open } \\
\quad(\mathrm{n}=19)\end{array}$} & $\mathrm{X}^{2}$ & p-value \\
\hline \multirow[t]{3}{*}{ PO complications } & No & 15 & $100 \%$ & 43 & $93.5 \%$ & 17 & $89.5 \%$ & \multirow[t]{3}{*}{1.79} & \multirow{3}{*}{$\begin{array}{c}0.773 \\
\text { NS }\end{array}$} \\
\hline & Leak & 0 & $0 \%$ & 1 & $2.2 \%$ & 1 & $5.3 \%$ & & \\
\hline & Collection & 0 & $0 \%$ & 2 & $4.3 \%$ & 1 & $5.3 \%$ & & \\
\hline
\end{tabular}

$\mathrm{X}^{2}$ : Chi-square test.

NS: p-value $>0.05$ is considered non-significant.

This table shows no statistical significant difference (p-value $>\mathbf{0 . 0 5}$ ) between studied groups as regard postoperative complications.

\section{DISCUSSION:}

Laparoscopy can be used as a diagnostic and therapeutic tool. It is universally known to result in a shorter hospital stay, fewer complications and reduced costs. Wiewióra report that laparoscopy is useful in revealing, "the kind of injury, its location and severity" and allows the treatment of minor injuries ${ }^{(7)}$.

In a systematic review published by O'Malley et al, 51 studies are included of which 13 are prospective trials. $43.95 \%$ of the total patients evaluated within the review were found to have injuries through laparoscopy of which $33.8 \%$ were subsequently treated by laparotomy. The authors conclude that although more evidence of a higher quality is needed laparoscopy has, "screening, diagnostic and therapeutic roles, when conducted by a proficient surgeon and can be used, "in determining the need for laparotomy but detects hollow visceral injuries less reliably ${ }^{(\mathbf{8})}$.

In our study results of 80 patients showed 15 patients $(18.8 \%)$ were negative, 65 patients $(81.3 \%)$ had positive finding 46 patients $(57.5 \%)$ were managed by laparoscopy and 19 patients $(23.8 \%)$ were converted to open surgery, so 61 patients (76.3\%) ovoid unnecessary laparotomy [15 negative $(8.8 \%)+46(57.5 \%)$ underwent laparoscopic management] so it's proved to both diagnostic and therapeutic role. 46 patients were managed by laparoscopy 12 (15\%) patients underwent repair of serosal and small tears with simple intracoporcal suturing, 10 patients $(12.5 \%)$ with omental injury, cauterization was done to the 8 patients and clipping of omental bleeder in 2 patients was done, 8 patients $(10 \%)$ with gastric tear were repaired by intracoporial suturing, 11 patients (13.8\%) with liver injury, haemostasis was done by cauterization and gel foam, 5 patients with left colonic and sigmoid injuries underwent lap. colostomy. 
A retrospective study conducted over 10 years was published by Johnson et al and concluded that laparoscopy is a useful diagnostic and therapeutic surgical tool. 70\% of patients can avoid traditional laparotomy when explorations indicated. The relative morbidity and mortality, complication rates, and missed injury rates are low and comparable with open approaches. Additionally, a wide variety of intra-abdominal pathology can be addressed ${ }^{(\mathbf{9})}$.

No complications related to the procedure in our study.

However complications of the procedure have also been listed and include gas embolism and tension pneumothorax specifically in patients with diaphragmatic injury due to the pneumoperitoneum created to conduct the surgery. Intracranial hypertension is a fatal possibility and Johnson et al recommend the avoidance of $\mathrm{CO} 2$ pneumoperitoneum in the evaluation of patients with head injuries ${ }^{(9)}$.

In our study 19 patients $(23.8 \%)$ were converted to open surgery, 14 patients $(17.5 \%)$ with intestinal injury underwent resection anastomosis, 5 patients $(6.25 \%)$ with right colonic injuries underwent right hemicolectomy due to lack of staplers and technical difficulties.

In a meta-analysis, 2569 patients underwent diagnostic laparoscopy (DL) for penetrating abdominal trauma (PAT), 1129 $(43.95 \%)$ was positive for injury. $13.8 \%$ of those with injury had a therapeutic laparoscopy. In total $33.8 \%$ were converted to laparotomy, $16 \%$ of which were nontherapeutic and $11.5 \%$ of them were negative. 1497 patients $(58.27 \%)$ were spared a non-therapeutic laparotomy ${ }^{(8)}$.

Since this study is a single-institution experience achieved by surgeons who are skilled in laparoscopic techniques, it should be interpreted with caution as such results may not be readily reproduced in other trauma centers.
So, training needs to be an issue to attend to early in the implementation of that technique in any trauma center. The provision of adequate laparoscopy training and skill development of trauma surgeons will ensure its safe adoption into our surgical community's realm of safe procedures.

Further studies with larger scales, and less variables should be carried out to ensure safe implementation of this protocol. Though not feasible in a trauma setting, allowing only one surgeon to perform all the laparoscopic explorations in the study would definitely decrease variables and result in more accurate results as well.

\section{Conclusion:}

Exploratory laparoscopy applied to carefully selected hemodynamically stable penetrating trauma patients proved to be safe and technically feasible. It also reduced the negative and non-therapeutic laparotomies and offered profound therapeutic potential and cost effectiveness. Laparoscopy is the satisfactory tool as both diagnostic in violating abdominal stab wounds in heamodynamically stable patients.

\section{REFERENCES:}

1. Fabian TC, Croce MA, Stewart RM. A prospective analysis of diagnostic laparoscopy in trauma. Am Surg., 1993; 217: 557-565.

2. Butt M., Nikoloas Z., George V. Penetrating abdominal injuries: management controversies. Scand. J. Trauma, Resuscitation and Emergency Medicine, 2009; 17:19.

3. Oestern HJ, Trentz OL, Uranues S. Head, Thoracic, Abdominal, and Vascular Injuries, Trauma Surgery I, laparoscopic procedures in trauma care, European Manual of Medicine, 2011; 13; 243-249.

4. Selman U, Dorin EP, Bogdan D, Rudolph S. Laparoscopy in penetrating abdominal trauma. World Journal of Surgery, 2015; 39(6): $1381-1388$. 


\section{Emad El-din Farid, et al.}

5. Letoublon C, Chen Y, Arvieux C, et al. Delayed celiotomy or laparoscopy as part of the nonoperative management of blunt hepatic trauma. World J Surg 2008; 32:1189-93.

6. Chol YB, Lim KS. Therapeutic laparoscopy for abdominal trauma. Surg Endosc., 2002;17(3):421-27.

7. Wiewióra M, Sosada K. The role of laparoscopy in abdominal trauma - review of the literature. Videosurgery and other mini invasive techniques. 2011; 6(3):121-6.

8. O'Malley, Boyle E. Role of laparoscopy in penetrating abdominal trauma: a systematic review. World J Surg., 2013;37(1):113-22.

9. Johnson JJ, Garwe T. The use of laparoscopy in the diagnosis and treatment of blunt and penetrating abdominal injuries: 10-year experience at a level 1 trauma center. Amer J Surg., 2013;205(3):317-21.

\section{تقييم دور منظار البطن الجراحي فى إصابات البطن النافذة للحالات المستثرة عماد الدين فريد, شعبان محمد محمد عبد المجيد, دينا هاني أحمد, محمد كامل سفينة عبد السيد

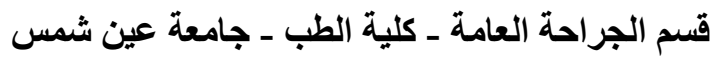

الخلفية العلمية: هناك الكثير من الطرق التشخيصية لتقييم المرضى ذوي الجروح النافذة بجدار البطن الامامي.

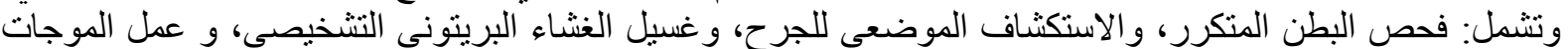

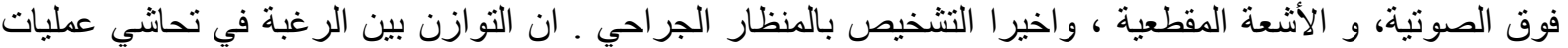

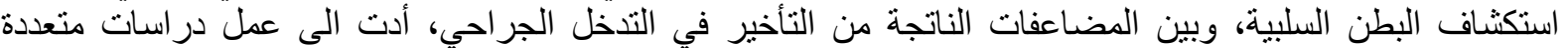
للمقارنة بين كل الطرق السابق ذكر ها للتشخيص.

الهرف من البحث: في دراستنا، كان هدفنا أن نحدد درجة الدقة و الاعتماد على المنظار الجراحي في نتخيص و علاج اختراق الغشاء البريتوني و اصني درابات الاعضاء هضاء الداخلية.

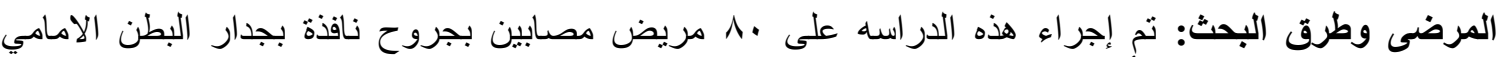

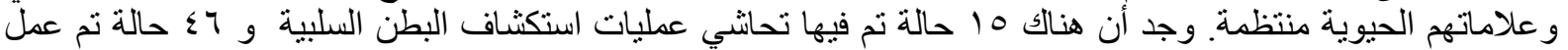

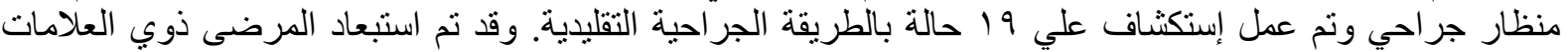

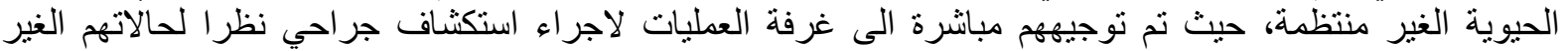

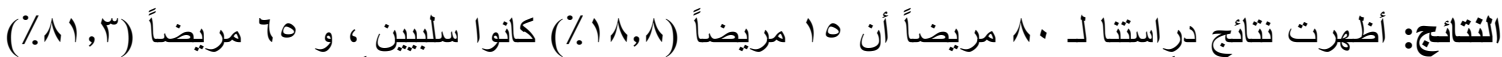

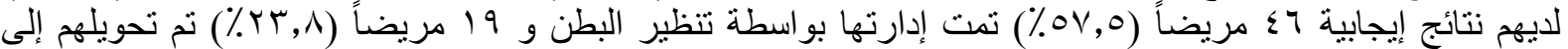

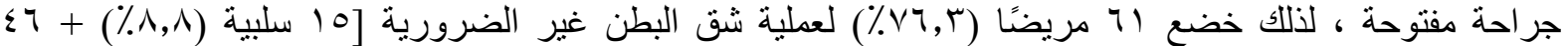

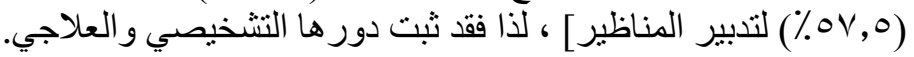

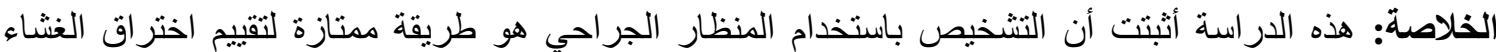

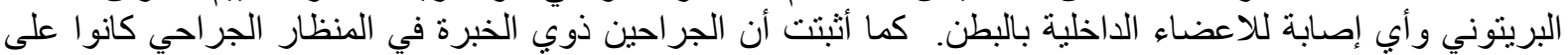

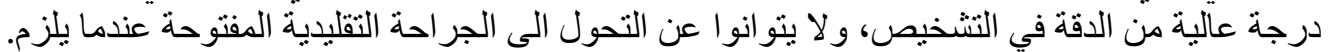

